\title{
Preparation of Polysaccharide-Based Microspheres by a Water-in-Oil Emulsion Solvent Diffusion Method for Drug Carriers
}

\author{
Yodthong Baimark and Yaowalak Srisuwan \\ Biodegradable Polymers Research Unit, Department of Chemistry and Center of Excellence for Innovation in Chemistry, \\ Faculty of Science, Mahasarakham University, Mahasarakham 44150, Thailand
}

Correspondence should be addressed to Yodthong Baimark; yodthong.b@msu.ac.th

Received 3 May 2013; Revised 24 July 2013; Accepted 29 July 2013

Academic Editor: Yulin Deng

Copyright (C) 2013 Y. Baimark and Y. Srisuwan. This is an open access article distributed under the Creative Commons Attribution License, which permits unrestricted use, distribution, and reproduction in any medium, provided the original work is properly cited.

Polysaccharide-based microspheres of chitosan, starch, and alginate were prepared by the water-in-oil emulsion solvent diffusion method for use as drug carriers. Blue dextran was used as a water-soluble biomacromolecular drug model. Scanning electron microscopy showed sizes of the resultant microspheres that were approximately $100 \mu \mathrm{m}$ or less. They were spherical in shape with a rough surface and good dispersibility. Microsphere matrices were shown as a sponge. Drug loading efficiencies of all the microspheres were higher than $80 \%$, which suggested that this method has potential to prepare polysaccharide-based microspheres containing a biomacromolecular drug model for drug delivery applications.

\section{Introduction}

During the past few decades, research interest in biodegradable polymeric microspheres has increased steadily as their potential in a wide range of biomedical applications has been realized [1]. Research related to encapsulation of watersoluble biomacromolecular active agents with hydrophilic polymeric microspheres for drug delivery has been widely investigated. The specific requirements, such as swelling and dissolution, of these hydrophilic microspheres can be tailored by the polymer blending and cross-linking methods $[2,3]$. Polysaccharides are common and cheap biopolymers that have been widely investigated as a microsphere matrix to carry water-soluble model drugs. Polysaccharide-based microspheres of chitosan [4-12], starch [13], and alginate $[2,14,15]$ have been used as biodegradable matrices for controlled release drug delivery. Several methods have been reported for preparing the polysaccharide-based microspheres, such as spray-drying, emulsification-precipitation, and emulsification-cross-linking methods $[4,13,16,17]$. However, a suitable method for fabricating polysaccharidebased microspheres remains a major challenge in the field of microencapsulation, especially a method that can be used for various polysaccharide types. Moreover, drug loading efficiency is also an important factor for consideration.

Recently, a water-in-oil (W/O) emulsion solvent diffusion method used to prepare water-soluble polymeric microspheres has been reported by our group $[18,19]$. This method is simple, rapid, and low in cost. Heat, high-energy and highcost apparatus, and the surfactant can be avoided, while the time is also reduced. Thus, it is suitable for larger-scale microsphere production.

In this work, we report that this single-step W/O emulsion solvent diffusion method can be used to prepare various polysaccharide-based microspheres with and without biomacromolecular drug entrapment. Polysaccharide samples including chitosan (cationic polysaccharide), starch (neutral polysaccharide), and alginate (anionic polysaccharide) were investigated in this work. Drug loading efficiency of the microspheres was determined for comparison.

\section{Materials and Methods}

2.1. Materials. Chitosans with molecular weights of 15 and $100 \mathrm{kDa}$ and $85-90 \%$ degree of deacetylation were purchased from Seafresh Chitosan Lab Co., Ltd. (Thailand). 
Potato starch (Fluka), sodium alginate (Carlo Erba, batch no. 7L096277M), blue dextran (GE Healthcare Bio-Sciences $A B)$, and ethyl acetate (AR, Lab Scan) were used without further purification. The intrinsic viscosity of the sodium alginate measured in $0.1 \mathrm{M} \mathrm{NaCl}$ at $25^{\circ} \mathrm{C}$ using an Ubbelohde viscometer was $850 \mathrm{~mL} / \mathrm{g}$.

2.2. Preparation of Microspheres. An acetic acid solution $(2 \% \mathrm{v} / \mathrm{v})$ was used as a solvent to prepare the chitosan solution. Potato starch and sodium alginate solutions were prepared by dissolving in distilled water. The polysaccharidebased microspheres were prepared by the water-in-oil (W/O) emulsion solvent diffusion method without any surfactants at $25^{\circ} \mathrm{C}$. In a typical procedure, $0.5 \mathrm{~mL}$ of polysaccharide solution $(0.5 \% \mathrm{w} / \mathrm{v})$ was slowly added dropwise to $100 \mathrm{~mL}$ of ethyl acetate with magnetic stirring at $900 \mathrm{rpm}$. The beaker was tightly sealed with aluminum foil to prevent evaporation of ethyl acetate during the emulsification-diffusion process for $1 \mathrm{~h}$. The microspheres suspended in ethyl acetate were collected by centrifugation before drying in a vacuum oven overnight. For drug encapsulation, blue dextran, the drug model was directly dissolved in the polysaccharide solution before microsphere formation. Polysaccharide/drug ratio was kept constant at 9/1 w/w.

2.3. Characterization of Microspheres. Morphology of the microspheres was investigated by scanning electron microscopy (SEM) using a JEOL JSM-6460LV SEM. The microspheres were coated with gold before scanning to enhance their conductivity. Average particle size and standard deviation (SD) were measured from several SEM images by counting a minimum of 100 particles using the Smile View software (version 1.02).

Actual drug loading content (DLC $\mathrm{Dctual})$ and drug loading efficiency (DLE) of the microspheres were determined by UV-vis spectrophotometry at a $\lambda_{\max }$ of $620 \mathrm{~nm}$ after completely dissolving the drug-loaded microspheres in an appropriate solvent under vigorous stirring for $48 \mathrm{~h}$. The chitosan microspheres were dissolved in $2 \%(\mathrm{v} / \mathrm{v})$ acetic acid solution, while the starch and alginate microspheres were dissolved in distilled water. A clear solution was obtained

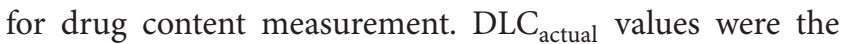
average from three experiments. Theoretical drug loading content $\left(\mathrm{DLC}_{\text {theoretical }}\right)$ and $\mathrm{DLC}_{\text {actual }}$ calculated from (1) and (2), respectively, were used to determine the DLE as in (3).

Consider the following:

$$
\begin{aligned}
& \mathrm{DLC}_{\text {theoretical }}(\%) \\
& =\frac{\text { feed drug }(\mathrm{mg})}{\text { feed polysaccharide }+ \text { feed } \operatorname{drug}(\mathrm{mg})} \times 100, \\
& \mathrm{DLC}_{\text {actual }}(\%) \\
& =\frac{\text { entrapped drug }(\mathrm{mg})}{\mathrm{drug}-\text { loaded microspheres }(\mathrm{mg})} \times 100, \\
& \mathrm{DLE}(\%)=\frac{\mathrm{DLC}_{\text {actual }}}{\mathrm{DLC}_{\text {theoretical }}} \times 100 .
\end{aligned}
$$

TABLE 1: Average particle size of polysaccharide-based microspheres.

\begin{tabular}{lcc}
\hline \multirow{2}{*}{ Polysaccharide } & \multicolumn{2}{c}{ Average particle size \pm SD $(\mu \mathrm{m})$} \\
& Drug-free & Drug loaded \\
\hline $15 \mathrm{kDa}$ chitosan & $28 \pm 15$ & $25 \pm 14$ \\
$100 \mathrm{kDa}$ chitosan & $52 \pm 12$ & $54 \pm 15$ \\
Potato starch & $34 \pm 10$ & $32 \pm 14$ \\
Alginate & $108 \pm 18$ & $112 \pm 22$ \\
\hline
\end{tabular}

\section{Results and Discussion}

For the W/O emulsion solvent diffusion method, the polysaccharide-based microspheres were formed after diffusion out of water from emulsion droplets of polysaccharide aqueous solution to the continuous oil phase, ethyl acetate. Then, resultant microspheres suspended in ethyl acetate were obtained with yields higher than $95 \%$. In a preliminary study, the yields decreased steadily as polysaccharide concentration and water phase volume increased. Particle aggregates on the inner wall and bottom of the beaker were found.

Morphology of the plain polysaccharide-based microspheres was determined by SEM, as illustrated in Figure 1. It can be observed that they were spherical in shape with good dispersibility. Table 1 reports the average particle sizes of the microspheres. For drug-free microspheres, the particle sizes were less than $100 \mu \mathrm{m}$ for chitosan and starch microspheres and approximately $100 \mu \mathrm{m}$ for alginate microspheres. The $15 \mathrm{kDa}$ chitosan microspheres were smaller in size than those of the $100 \mathrm{kDa}$ chitosan microspheres. This suggests that the particle size of the microspheres strongly depended on the polymer molecular weight, which is directly related to the solution viscosity. The highly viscous polysaccharide solution is difficult to emulsify into small emulsion droplets. It can be concluded that more viscous polysaccharide solutions induced larger-sized microspheres.

Figure 2 shows the rough surfaces of the polysaccharidebased microspheres. This surface roughness may occur due to the diffusion out of the water in emulsion droplets to the ethyl acetate continuous phase during solidification of microsphere matrices. The internal morphology of the microspheres can be observed from broken microspheres, as shown in Figure 3. It can be clearly seen that the microsphere matrices had a porous structure similar to a sponge. It could be proposed that the microsphere densities were lower than those of the substances that they were formed from. The results suggest that this method can be used to prepare lowdensity polysaccharide-based microspheres.

The internal porous structure of microspheres may form due to phase separation taking place in the emulsion droplets during the emulsification-diffusion stages. The porous structure could form when a small amount of nonsolvent (ethyl acetate) diffused into each emulsion droplet and worsened the solubility of the polysaccharide. Then, the polysaccharide solidified and precipitated rapidly. However, the porous matrices were completely covered with a continuous rough surface. 


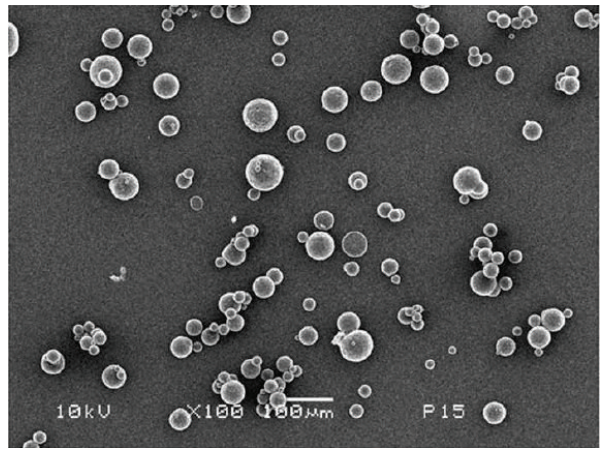

(a)

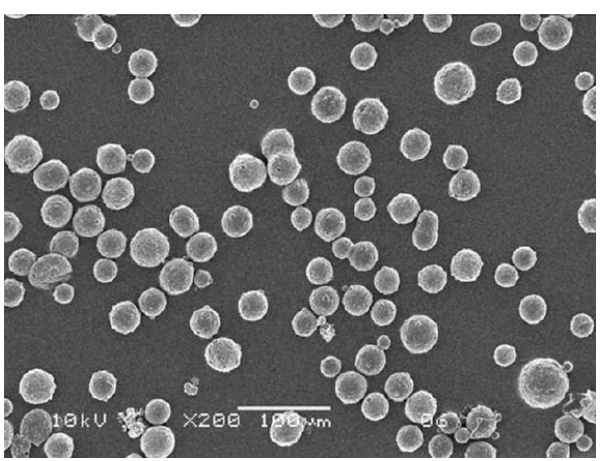

(c)

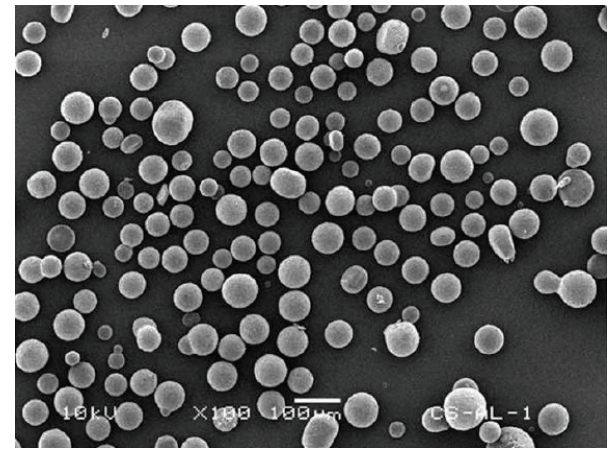

(b)

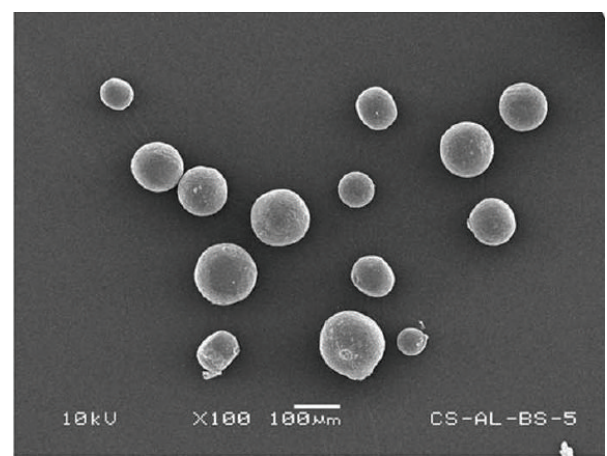

(d)

Figure 1: SEM images of drug-free microspheres of (a) $15 \mathrm{kDa}$ chitosan, (b) $100 \mathrm{kDa}$ chitosan, (c) potato starch, and (d) alginate. All bars = $100 \mu \mathrm{m}$.

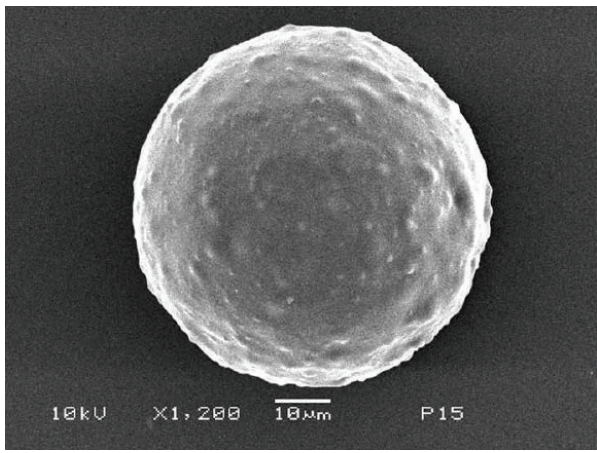

(a)

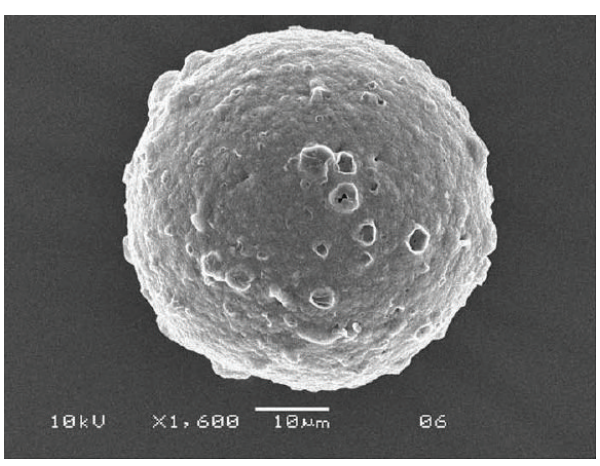

(c)

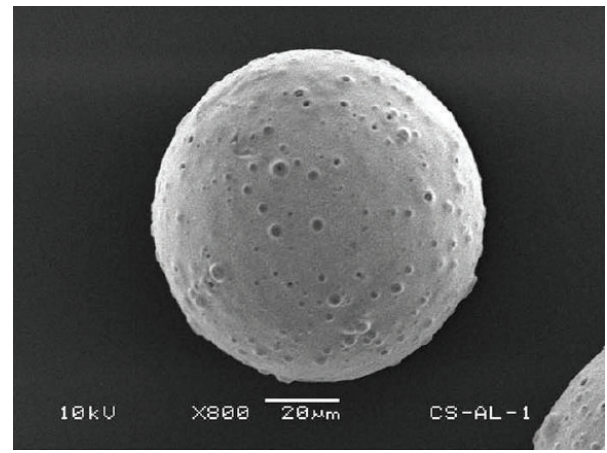

(b)

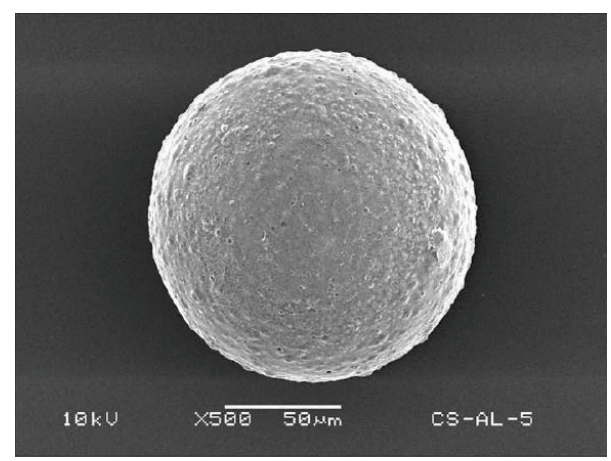

(d)

Figure 2: Expanded SEM images of drug-free microspheres of (a) $15 \mathrm{kDa}$ chitosan, (b) $100 \mathrm{kDa}$ chitosan, (c) potato starch, and (d) alginate. Bars $=10 \mu \mathrm{m}$ for (a) and (c), $20 \mu \mathrm{m}$ for (b), and $50 \mu \mathrm{m}$ for (d). 


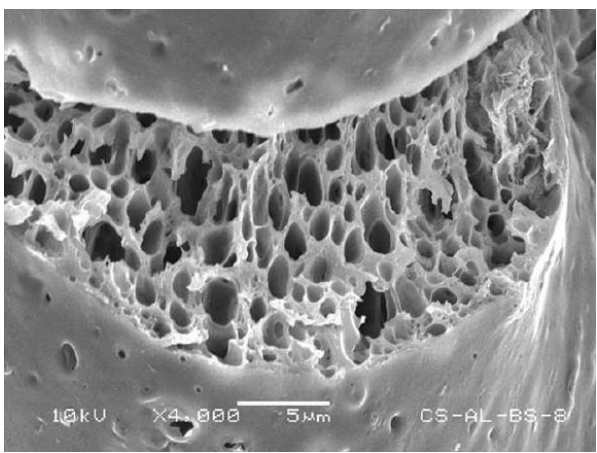

(a)

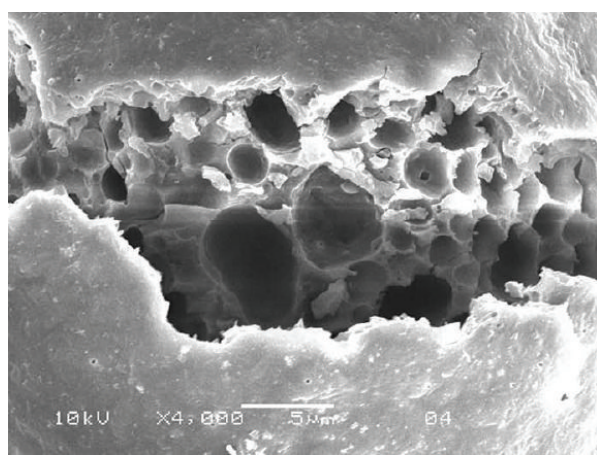

(c)

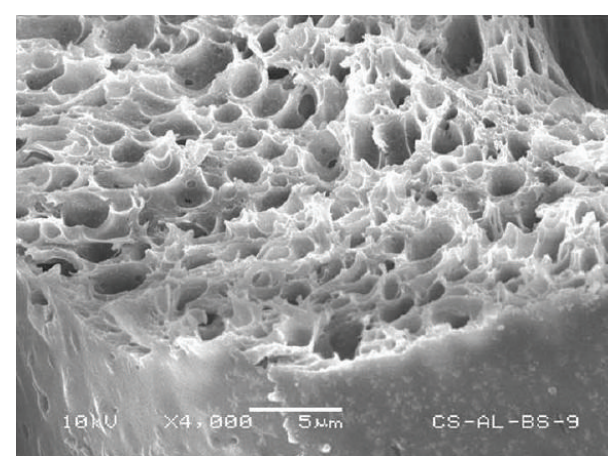

(b)

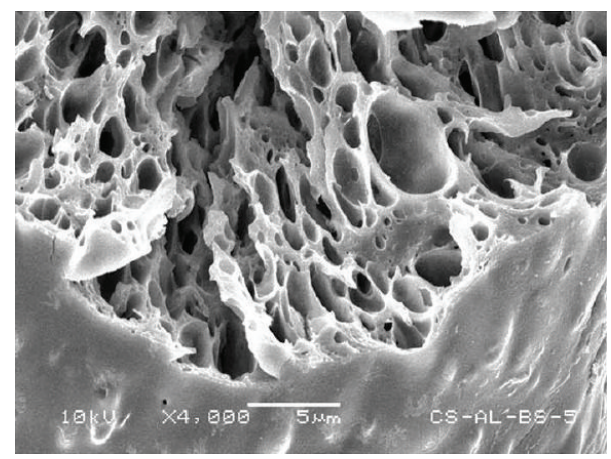

(d)

Figure 3: SEM images of broken drug-free microspheres of (a) $15 \mathrm{kDa}$ chitosan, (b) $100 \mathrm{kDa}$ chitosan, (c) potato starch, and (d) alginate. All bars $=5 \mu \mathrm{m}$.

For the morphology of polysaccharide-based microspheres containing blue dextran, a water-soluble biomacromolecular drug model is illustrated in Figure 4. The particle morphology and dispersibility of drug-loaded microspheres were similar to the drug-free microspheres. This indicates that the drug entrapment did not affect morphology and dispersibility of polysaccharide-based microspheres. In addition, the particle sizes did not change significantly after drug entrapment (see Table 1).

The obtained chitosan microspheres with and without drug entrapment can completely dissolve in acetic aqueous solution, while the starch and alginate microspheres can completely dissolve in distilled water. The dissolution results suggested that this preparation method did not affect the solubility of the polysaccharide matrices.

Actual drug loading content ( $\mathrm{DLC}_{\text {actual }}$ ) in the microspheres was measured by completely dissolving the drugloaded microspheres before determining the drug content. The $\mathrm{DLC}_{\text {actual }}$ results of $15 \mathrm{kDa}$ chitosan, $100 \mathrm{kDa}$ chitosan, starch, and alginate were $8.79,9.23,8.95$, and $8.18 \%$, respectively. The theoretical DLC ( DLC $\left._{\text {theoretical }}\right)$ of all the polysaccharide-based microspheres was the same, $10 \%$. Drug loading efficiencies (DLE) calculated from the percentage of the $\mathrm{DLC}_{\text {actual }} / \mathrm{DLC}_{\text {theoretical }}$ ratio are summarized in Figure 5. Results of calculated DLE are in the range $82-92 \%$. The results indicate that the polysaccharide-based microspheres with high drug loading efficiency can be prepared by the W/O emulsification-diffusion method for use as biomacromolecular drug carriers.
It is well known that the swelling and dissolution of polysaccharide-based microspheres, which is directly related to the drug release rates, could be tailored by adjusting the degree of cross-linking. The swelling and dissolution of these polysaccharide-based microspheres could be controlled by cross-linking before or after microsphere formation. Sodium tripolyphosphate [20], trimetaphosphate [13], and calcium ions [15] have been used as cross-linkers of chitosan, starch, and alginate, respectively.

Finally, it is important to note that it is possible to prepare blended polysaccharide-based microspheres via this method to enhance the required physical-chemical properties. For this purpose, the polysaccharide solutions were mixed before microsphere preparation. Therefore, novel blended polysaccharide-based microspheres should be investigated for specific biomedical, pharmaceutical, and adsorbent applications.

\section{Conclusions}

In summary, this work has demonstrated that a simple $\mathrm{W} / \mathrm{O}$ emulsion solvent diffusion method shows potential as a method to prepare drug-free and drug-loaded microspheres of chitosan, starch, and alginate. The microspheres were spherical in shape with fine dispersibility. The microsphere sizes depended on the molecular weight of the polysaccharide. By this method, it will be possible to prepare drugloaded polysaccharide-based microspheres with high drug 


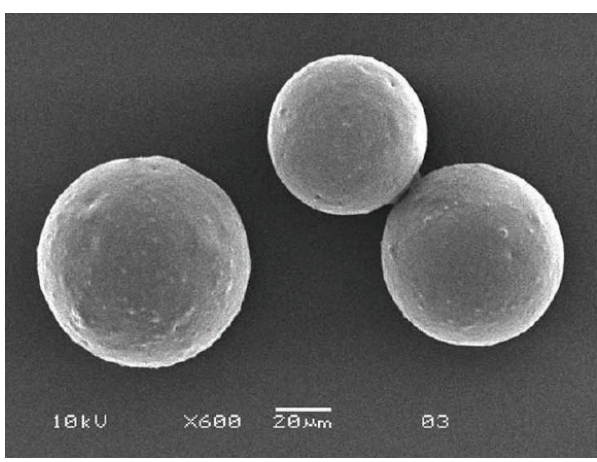

(a)

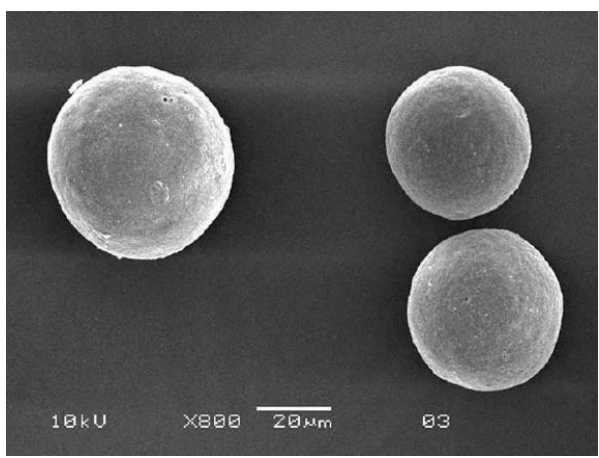

(c)

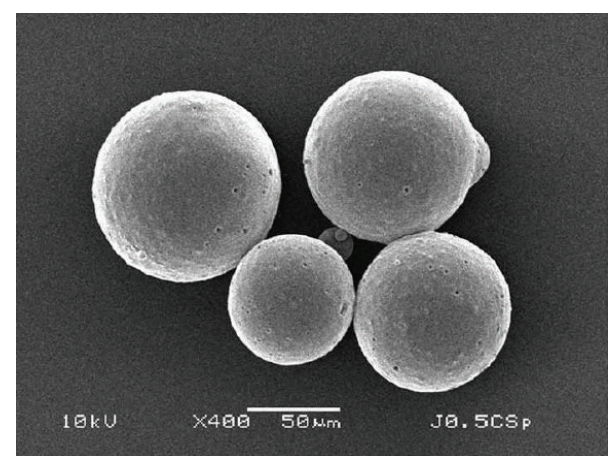

(b)

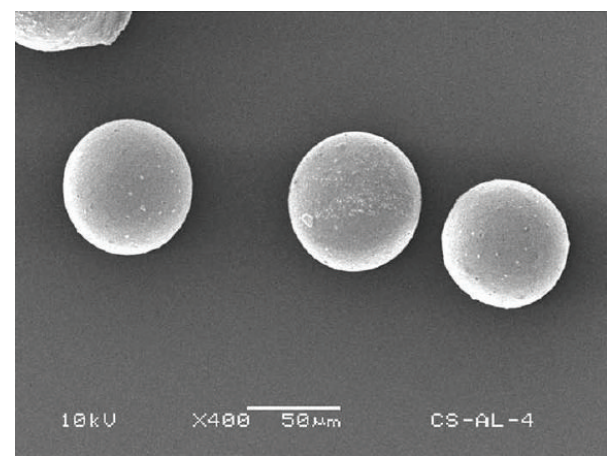

(d)

Figure 4: SEM images of drug-loaded microspheres of (a) $15 \mathrm{kDa}$ chitosan, (b) $100 \mathrm{kDa}$ chitosan, (c) potato starch, and (d) alginate. Bars = $20 \mu \mathrm{m}$ for (a) and (c), and $50 \mu \mathrm{m}$ for (b) and (d).

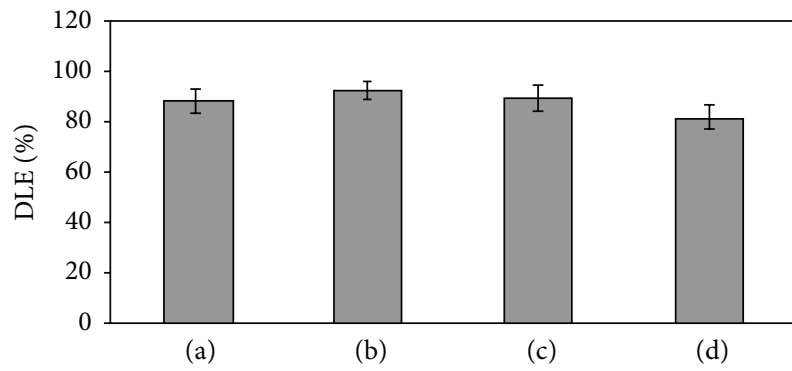

FIGURE 5: DLE of drug-loaded microspheres of (a) $15 \mathrm{kDa}$ chitosan, (b) $100 \mathrm{kDa}$ chitosan, (c) potato starch, and (d) alginate.

loading efficiencies for drug delivery applications. The crosslinking and drug release behaviors of these microspheres for use as drug carriers are under investigation.

\section{Acknowledgments}

This work was financially supported by the Office of the Higher Education Commission, Ministry of Education, Thailand, to Mahasarakham University. The Center of Excellence for Innovation in Chemistry (PERCH-CIC), Commission on Higher Education, Ministry of Education, Thailand, is also acknowledged.

\section{References}

[1] K. Z. Gumargalieva, D. Horak, and G. E. Zaikov, “Biodegradable polymeric microparticles in biomedical applications," International Journal of Polymeric Materials, vol. 42, no. 1-2, pp. 83-117, 1998.

[2] Y. Xu, C. Zhan, L. Fan, L. Wang, and H. Zheng, "Preparation of dual crosslinked alginate-chitosan blend gel beads and in vitro controlled release in oral site-specific drug delivery system," International Journal of Pharmaceutics, vol. 336, no. 2, pp. 329337, 2007

[3] A. Roy, J. Bajpai, and A. K. Bajpai, "Dynamics of controlled release of chlorpyrifos from swelling and eroding biopolymeric microspheres of calcium alginate and starch," Carbohydrate Polymers, vol. 76, no. 2, pp. 222-231, 2009.

[4] S. A. Agnihotri, N. N. Mallikarjuna, and T. M. Aminabhavi, "Recent advances on chitosan-based micro- and nanoparticles in drug delivery," Journal of Controlled Release, vol. 100, no. 1, pp. 5-28, 2004.

[5] S. G. Kumbar and T. M. Aminabhavi, "Synthesis and characterization of modified chitosan microspheres: effect of the grafting ratio on the controlled release of nifedipine through microspheres," Journal of Applied Polymer Science, vol. 89, no. 11, pp. 2940-2949, 2003.

[6] S. A. Agnihotri and T. M. Aminabhavi, "Controlled release of clozapine through chitosan microparticles prepared by a novel method," Journal of Controlled Release, vol. 96, no. 2, pp. 245259, 2004. 
[7] K. S. V. Krishna Rao, B. Vijaya Kumar Naidu, M. C. S. Subha, M. Sairam, and T. M. Aminabhavi, "Novel chitosan-based pHsensitive interpenetrating network microgels for the controlled release of cefadroxil," Carbohydrate Polymers, vol. 66, no. 3, pp. 333-344, 2006.

[8] A. Rokhade, N. Shelke, S. Patil, and T. Aminabhavi, "Novel hydrogel microspheres of chitosan and pluronic F-127 for controlled release of 5-fluorouracil," Journal of Microencapsulation, vol. 24, no. 3, pp. 274-288, 2007.

[9] A. P. Rokhade, P. V. Kulkarni, N. N. Mallikarjuna, and T. M. Aminabhavi, "Preparation and characterization of novel semiinterpenetrating polymer network hydrogel microspheres of chitosan and hydroxypropyl cellulose for controlled release of chlorothiazide," Journal of Microencapsulation, vol. 26, no. 1, pp. 27-36, 2009.

[10] S. C. Angadi, L. S. Manjeshwar, and T. M. Aminabhavi, "Interpenetrating polymer network blend microspheres of chitosan and hydroxyethyl cellulose for controlled release of isoniazid," International Journal of Biological Macromolecules, vol. 47, no. 2, pp. 171-179, 2010.

[11] W. E. Rudzinski and T. M. Aminabhavi, "Chitosan as a carrier for targeted delivery of small interfering RNA," International Journal of Pharmaceutics, vol. 399, no. 1-2, pp. 1-11, 2010.

[12] K. Ganguly, T. M. Aminabhavi, and A. R. Kulkarni, "Colon targeting of 5-fluorouracil using polyethylene glycol cross-linked chitosan microspheres enteric coated with cellulose acetate phthalate," Industrial and Engineering Chemistry Research, vol. 50, no. 21, pp. 11797-11807, 2011.

[13] Y.-Y. Fang, L.-J. Wang, D. Li et al., "Preparation of crosslinked starch microspheres and their drug loading and releasing properties," Carbohydrate Polymers, vol. 74, no. 3, pp. 379-384, 2008.

[14] M. D. Kurkuri, A. R. Kulkarni, M. Y. Kariduraganavar, and T. M. Aminabhavi, "In vitro release study of verapamil hydrochloride through sodium alginate interpenetrating monolithic membranes," Drug Development and Industrial Pharmacy, vol. 27, no. 10, pp. 1107-1114, 2001.

[15] X. Zhang, Z. Hui, D. Wan et al., "Alginate microsphere filled with carbon nanotube as drug carrier," International Journal of Biological Macromolecules, vol. 47, no. 3, pp. 389-395, 2010.

[16] R. C. Mundargi, N. B. Shelke, A. P. Rokhade, S. A. Patil, and T. M. Aminabhavi, "Formulation and in-vitro evaluation of novel starch-based tableted microspheres for controlled release of ampicillin," Carbohydrate Polymers, vol. 71, no. 1, pp. 42-53, 2008.

[17] B.-Z. Li, L.-J. Wang, D. Li et al., "Fabrication of starch-based microparticles by an emulsification-crosslinking method," Journal of Food Engineering, vol. 92, no. 3, pp. 250-254, 2009.

[18] N. Kotsaeng, J. Karnchanajindanun, and Y. Baimark, "Chitosan microparticles prepared by the simple emulsification-diffusion method," Particulate Science and Technology, vol. 28, no. 4, pp. 369-378, 2010.

[19] J. Karnchanajindanun, M. Srisa-Ard, and Y. Baimark, "Genipincross-linked chitosan microspheres prepared by a water-inoil emulsion solvent diffusion method for protein delivery," Carbohydrate Polymers, vol. 85, no. 3, pp. 674-680, 2011.

[20] D. P. Chattopadhyay and M. S. Inamdar, "Aqueous behaviour of chitosan," International Journal of Polymer Science, vol. 2010, Article ID 939536, 7 pages, 2010. 

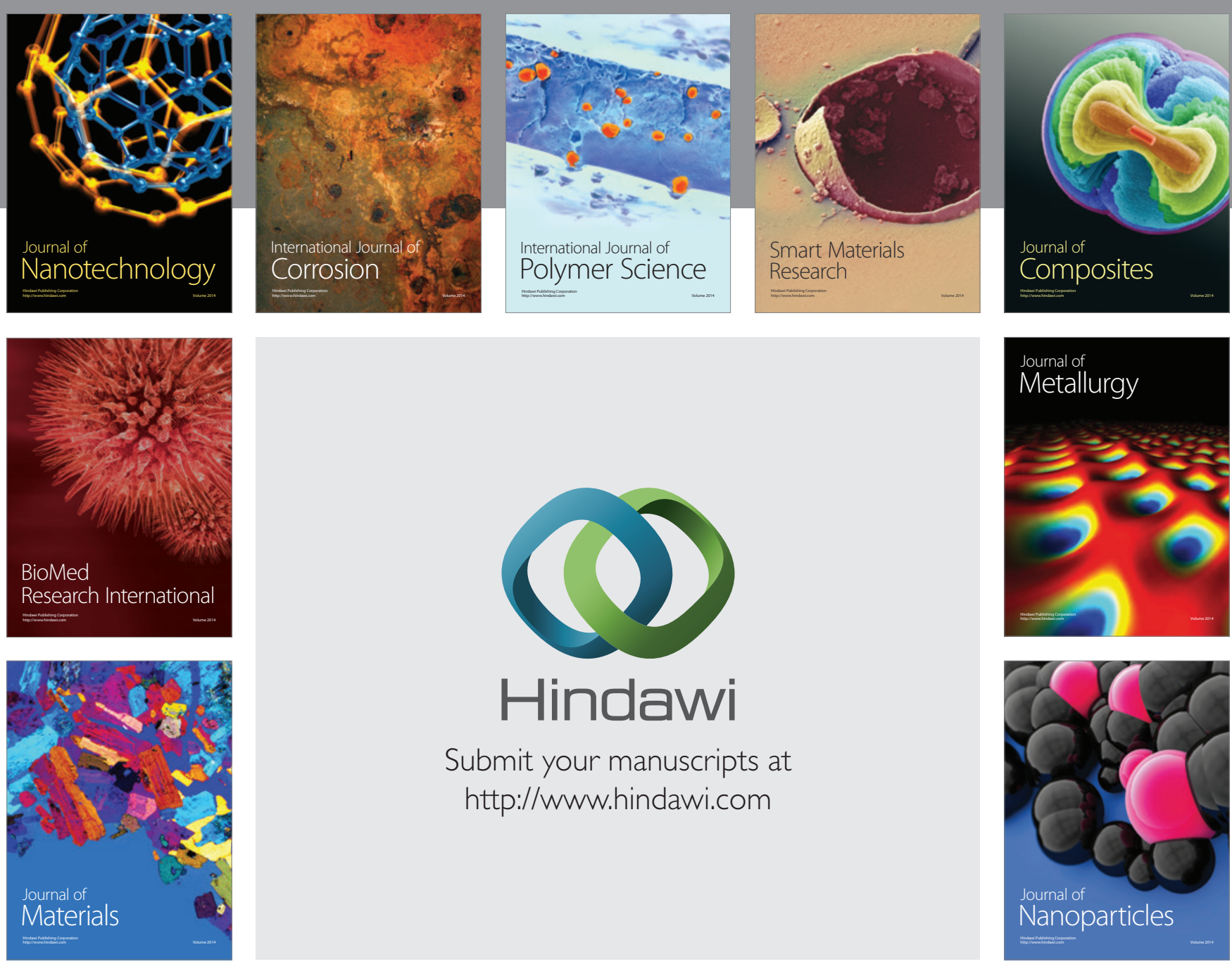

Submit your manuscripts at http://www.hindawi.com
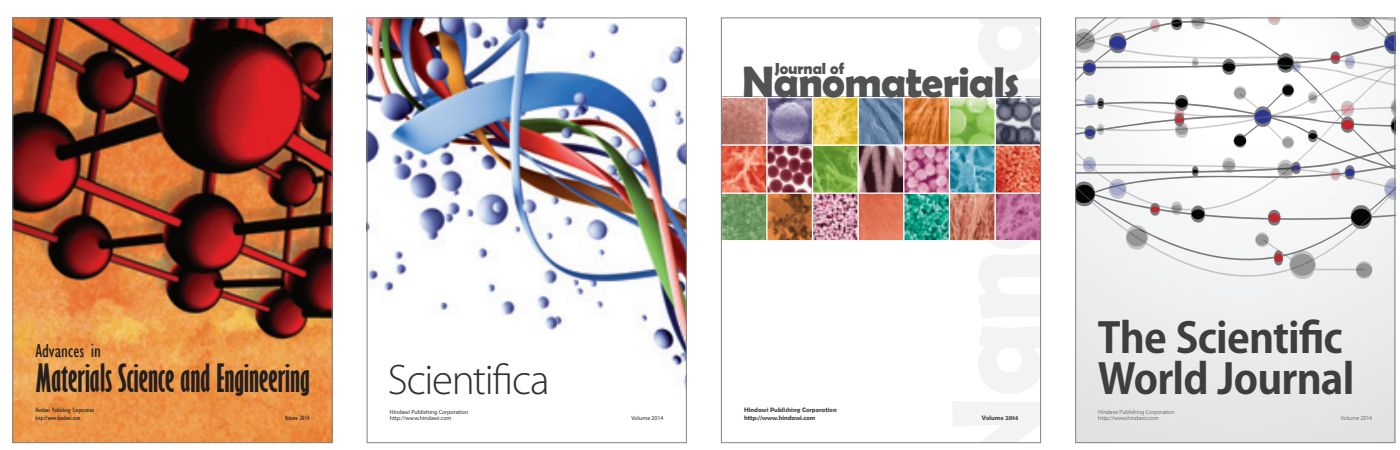

\section{The Scientific World Journal}
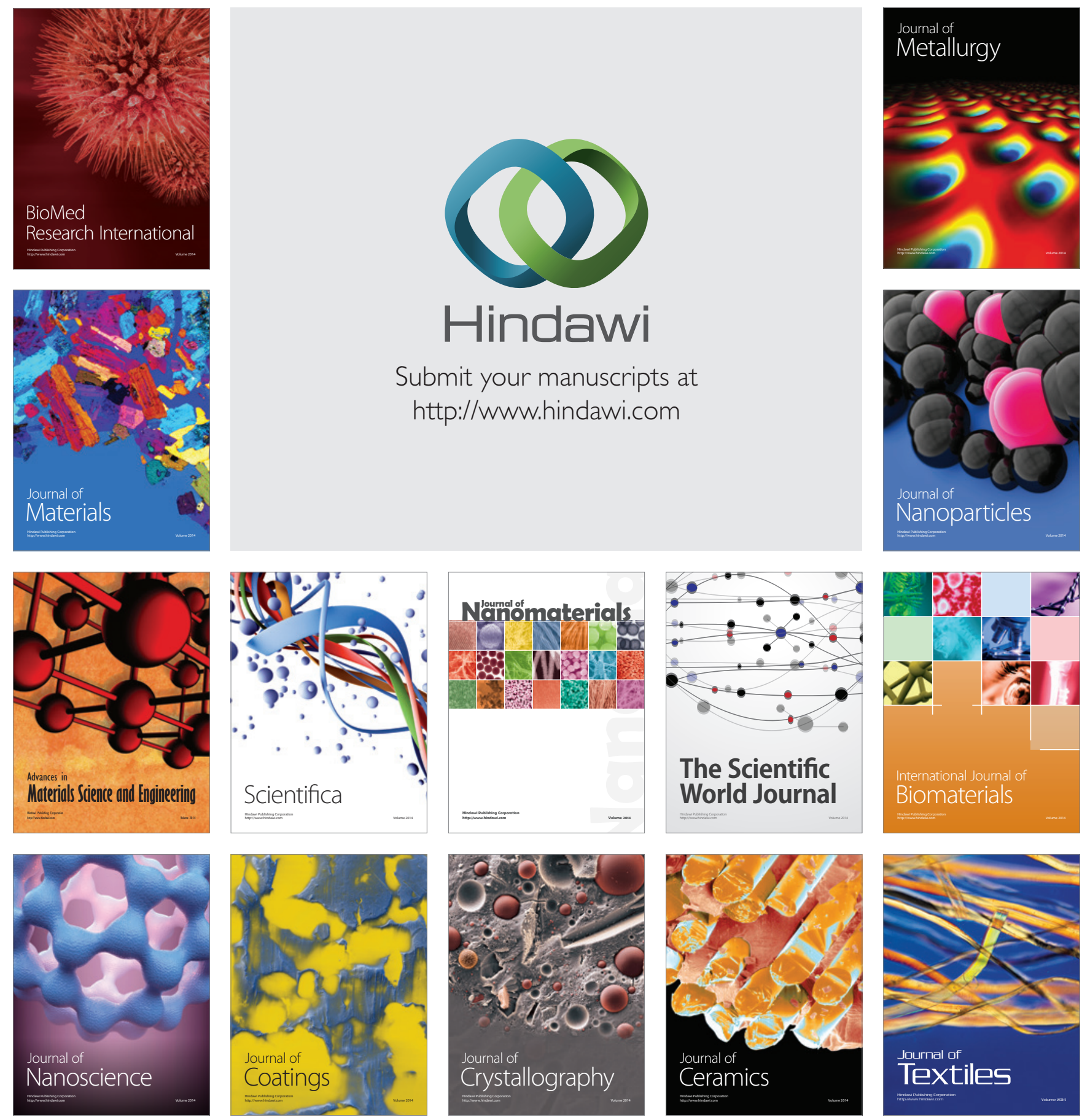